\title{
STRATEGI PEMASARAN UNTUK MEMPERTAHANKAN \\ MARKET LEADERSHIP
}

\author{
Sugino Gunawan \\ Alumnus, Program Magister Manajemen Universitas Bunda Mulia, Jakarta
}

\begin{abstract}
:
The increasing construction projects of office buildings that look very significant in Indonesia especially in Jakarta have made office furniture industry become more interesting. This case certainly become a gold opportunity for office furniture companies such as " $X$ ", but on the other hand, local companies also faced with bold competition from foreign countries, especially from China. " $X$ " is one of the oldest player in office furniture industry and also a market leader in the industry. It's also faced by a very tight competition both from local and abroad. It is very important for " $X$ " to expand its market share. The purpose of this study is to analyze the suitable marketing mix strategy to obtain market leadership in furniture business.
\end{abstract}

Keywords: furniture industry, market leader, market share, marketing mix strategy

\section{PENDAHULUAN}

Era globalisasi membuat setiap kalangan pebisnis harus selalu waspada dalam meningkatkan produktivitas serta efisiensi agar organisasi yang dikelolanya dapat bertahan. Hal ini dapat terjadi pada organisasi manapun, baik organisasi berskala kecil, menengah, maupun besar. Perkembangan pangsa pasar (market share) akan menjadi salah satu tolok ukur untuk mengetahui apakah kinerja dari organisasi tersebut telah optimal atau bahkan sebaliknya, oleh sebab itu suatu organisasi harus mengevaluasi ulang kinerja yang telh dicapainya khususnya pangsa pasar yang telah ada dan dipertahankan sampai saat ini. Disamping itu juga penting dalam memperhatikan dan mencari strategi-strategi yang terbaik serta inovatif untuk menghadapi persaingan yang semakin ketat, mempertahankan dan meningkatkan pangsa pasar yang telah dicapai selama ini.

Tahapan analisa terhadap market share dapat dilakukan dengan mengukur penjualan yang selama ini telah dicapai, tingkat pertumbuhan penjualan dalam periode tertentu, pertumbuhan jumlah pelanggan, serta pertambahan jenis produk. Dari hasil analisa tersebut, maka akan diketahui tingkat pertumbuhan dari market share yang telah dicapai oleh organisasi tersebut dalam periode waktu tertentu, yang kemudian akan dilakukan proses analisa berikutnya untuk mencari strategi yang tepat dan inovatif untuk menghadapi persaingan yang ketat, mempertahankan pangsa pasar yang ada serta meningkatkan pangsa pasar dimasa sekarang dan akan datang.

\section{TUJUAN DAN MANFAAT PENELITIAN}

Tujuan dan manfaat dilakukan penelitian ini adalah sebagai berikut:

1. Menganalisa tingkat pertumbuhan penjualan serta tingkat market share yang telah dicapai 
2. Mengetahui tingkat efektifitas dari strategi-strategi yang selama ini telah dilakukan

\section{TINJAUAN TEORITIS}

\section{Pengertian Manajemen Pemasaran}

Pemasaran merupakan proses sosial dan manajerial umum dimana individu dan kelompok mendapatkan apa yang mereka butuhkan dan inginkan melalui pertukaran produk dan nilai. Menurut Asosiasi Pemasaran Amerika, pengertian dari pemasaran adalah proses analisis, perencanaan, dan pelaksanaan dari perwujudan pemberian harga, promosi dan distribusi dari barang-barang, jasa dan gagasan untuk menciptakan pertukaran dengan kelompok sasaran yang memenuhi tujuan pelanggan dan perusahaan (Kotler, 2003:5). Untuk mencapai tujuan tersebut perlu didasari filosofi yang matang.

Ada enam konsep pemasaran yang mendasari cara organisasi melakukan kegiatan pemasarannya (Kotler, $2003: 17$ ), yaitu :

1. Konsep Berwawasan Produksi

Konsep ini berpendapat bahwa konsumen akan memilih produk yang mudah didapat dan murah harganya.

2. Konsep Berwawasan Produk

Konsep ini berpendapat bahwa konsumen akan memilih produk yang menawarkan mutu, kinerja dan hal-hal inovatif lainnya.

3. Konsep Berwawasan Penjualan

Konsep ini berpendapat bahwa konsumen enggan untuk membeli dan harus didorong supaya membeli, terkecuali perusahaan menjalankan suatu usaha promosi dan penjualan yang efektif untuk merangsang pembelian

4. Konsep Berwawasan Pemasaran

Kunci utama untuk mencapai tujuan perusahaan terdiri dari penentuan kebutuhan dan keinginan pasar serta memberikan kepuasan yang diinginkan secara lebih efektif dan efisien daripada competitor.

5. Konsep Berwawasan Konsumen

Untuk meningkatkan penjualan maka perusahaan harus fokus pada kebutuhan dan keinginan konsumen sehingga dapat menaikkan loyalitas konsumen.

6. Konsep Berwawasan Pemasaran Bermasyarakat

Konsep ini beranggapan bahwa tugas perusahaan adalah menentukan kebutuhan, keinginan, serta kepentingan pasar sasaran dan memenuhinya dengan lebih efektif serta lebih efisien daripada competitor dengan cara mempertahankan atau meningkatkan kesejahteraan konsumen dan masyarakat

\section{Brand awareness}

Brand awareness adalah kesanggupan seorang calon pembeli untuk mengenali, mengingat kembali suatu merek sebagai bagian dari suatu kategori produk tertentu (Durianto, Sugianto, dan Sitinjak, 2001: 54). Brand awareness mengacu kepada kekuatan dari kehadiran suatu merek didalam benak konsumen. Strategi yang sukses dari brand awareness harus dapat menjelaskan keunikan dari merek itu sendiri dan menjadikannya berbeda dari competitor yang ada. Awareness diukur berdasarkan cara-cara yang berbeda dimana konsumen mengingat suatu merek, dimulai dari regconition hingga proses recall pada benak utama yang dominan. 
Agar brand awareness dapat dicapai dan diperbaiki maka dapat ditempuh beberapa cara:

1. Pesan yang disampaikan harus mudah diingat dan tampil beda dibandingkan dengan lainnya, serta memiliki koneksi antara merek dengan kategori produknya.

2. Memakai slogan atau jingle lagu yang menarik sehingga konsumen terbantu untuk mengingat merek tersebut.

3. Jika produk memiliki simbol, sebiknya simbol yang dipakai dapat dihubungkan dengan mereknya.

4. Perluasan nama merek dapat dipakai agar merek semakin banyak diingat konsumen.

5. Brand awareness dapat diperkuat dengan memakai suatu isyarat yang sesuai dengan kategori produk, merek atau keduanya.

6. Melakukan pengulangan untuk meningkatkan pengingatan karena membentuk ingatan lebih sulit dibandingkan membentuk pengenalan.

\section{Segmentation, Targeting, Positioning (STP)}

Dalam sebuah proses untuk memasarkan produk ada tiga hal penting yang harus diperhatikan yaitu segmentation, targeting dan positioning. Sebuah perusahaan yang berperan sebagai produsen tentu tidak dapat melayani semua permintaan konsumen dalam pasar yang luas, sebab konsumen yang ada terlalu banyak dan sangat bervariasi keinginannya.

Oleh karena itu produsen harus dapat mengidentifikasi segmen pasar yang hendak dilayaninya dengan baik dan membaginya dalam kelompok-kelompok yang lebih kecil (segmentation), setelah itu produsen dapat mengevaluasi segmen pasar mana yang lebih menarik untuk dimasuki dan dapat memilih salah satu atau lebih segmen pasar yang ada (targeting). Sesudah kedua hal tersebut dilakukan, maka produsen dapat menetapkan posisi yang diinginkan atas produknya atau perusahaannya dalam benak konsumen, dibandingkan dengan pesaingnnya.

1. Segmentasi Pasar (Market Segmentatition)

Konsumen dalam sebuah pasar adalah heterogen dan dapat dikelompokkan menjadi kelompok konsumen yang homogen dengan berbagai cara. Kelompok konsumen ini dapat dibentuk atas dasar variable geografi (kota negera), variable demografis (umur, jenis kelamin, pendapatan), variable perilaku (tingkat pemakai).

2. Target Pasar (Market Targeting)

Setelah melakukan segmentasi pasar dan memisahkan konsumen dalam kelompok yang lebih kecil, maka langkah selanjutnya yang harus dilakukan oleh produsen adalah mengevaluasi setiap segmen pasar yang telah terbentuk dan memilih salah satu atau lebih segmen pasar yang hendak dimasuki

3. Posisi di Pasar (Market Positioning)

Dengan melakukan segementasi dan menentukan target pasar dengan baik maka produsen akan mendapatkan pengertian yang menyeluruh tentang kebutuhan, sikap dan perilaku sang konsumen. Bila sudah dapat mengerti apa yang diinginkan oleh konsumen maka sang produsen dapat menyelaraskannya dengan kemampuan sendiri dan menetapkan posisi produk dipasar. 


\section{Analisis SWOT (Strengths Weaknesses, Opportunities, Threats)}

Menurut Rangkuti $(1997,18)$ analisis SWOT adalah identifikasi berbagai faktor secara sistematis untuk merumuskan strategi perusahaan. Analisis ini didasarkan pada logika yang dapat memaksimalkan kekuatan (strengths) dan peluang (opportunities), namun secara bersamaan dapat meminimalkan kelemahan (weaknesses) dan ancaman (threats). Proses pengambilan keputusan strategis selalu berkaitan dengan pengembangan misi, tujuan, strategi dan kebijakan perusahaan. Dengan demikian maka perencana strategis (strategic planner) harus menganalisis faktor-faktor strategis perusahaan yang meliputi kekuatan, kelemahan, peluang dan ancaman yang ada dalam kondisi saat ini.

\section{Strategi Pertumbuhan Intensif (Intensive growth strategies)}

Dalam suatu perusahaan, pihak manajemen harus selalu melakukan evaluasi kinerja atas bisnis yang sedang berjalan, dengan demikian maka akan diketaui apakah bisnis yang berjalan mengalami pertumbuhan atau sebaliknya. Ansoff telah merumuskan sebuah matrix yang sangat berguna untuk mengetahui ada atau tidak adanya peluang pertumbuhan intensif dari suatu bisnis yang sering disebut sebagai "product market expansion grid" seperti gambar yang tertera dibawah ini

Tabel 1. Three Intensive Growth Strategies: Ansoff's Product Market Expansion Grid

\begin{tabular}{|c|l|l|}
\hline & \multicolumn{1}{|c|}{ Current Product } & \multicolumn{1}{c|}{ New Product } \\
\hline Current Market & 1. Market Penetration Strategy & 3. Product Development Strategy \\
\hline New Market & 2. Market Development Strategy & 4. Diversification Strategy \\
\hline
\end{tabular}

Pada awalnya, perusahaan akan mempertimbangkan apakah produknya masih mampu dalam meningkatkan pangsa pasar atau tidak pada pasar sekarang (market-penetration strategy), selanjutnya perusahaan akan mempertimbangkan untuk mengembangkan pasar yang baru dengan produk yang ada (market development strategy), kemudian perusahaan akan emeprtimbangkan untuk mengembangkan produk baru untuk pangsa pasar yang ada (product-development strategy), dan akhirnya perusahaan akan berusaha untuk mengembangkan produk baru dan pangsa pasarnya yang baru (diversification strategy)

\section{METODOLOGI PENELITIAN}

\section{Obyek Penelitian}

Penelitian dilakukan pada perusahaan $\mathrm{X}$ sebuah perusahaan manufaktur yang bergerak dalam bidang office furniture merek " $A$ " yang berlokasi di Jakarta. Penelitian dilakukan pada seluruh karyawan disamping itu juga dilakukan survey terhadap beberapa customer yang dibagi menjadi dua antara lain cutomer tetap dan customer yang memiliki potensi menjadi cutomer tetap perusahaan $\mathrm{X}$.

\section{Metode Pengumpulan Data}

Metode pengumpulan data pada penelitian ini akan dilakukan dengan beberapa metode dimana terdapat data internal, maupun data eksternal. Data internal diperoleh dari lingkungan internal perusahaan secara langsung, sedangkan data eksternal dikumpulkan dengan beberapa metode yang berasal dari lingkungan eksternal perusahaan tersebut. 
Secara rinci mengenai pengumpulan data yang akan dilakukan dalam penelitian ini :

- Data dari lingkungan internal

Data yang diperoleh dari lingkungan internal, meliputi data mengenai gambaran secara umum meliputi data profil perusahaan, visi dan misi, stuktur organisasi, laporan penjualan tahun, dan data yang berkaitan dengan marketing dan strategi perusahaan (business plan). Data tersebut sangat berguna dalam proses penelitian sebagai bahan untuk analisa terhadap masalah maupun strategi baru yang nantinya akan dirumuskan dan digunakan kemudian.

- Wawancara

Dalam penelitian ini juga akan dilakukan wawancara terhadap sebagian karyawan dan tim manajemen dari perusahaan yang terkait dalam bidang penelitian, dimana hasil dari wawancara ini akan dipakai sebagai bahan pertimbangan dalam memecahkan masalah yang sedang terjadi serta berguna juga sebagai bahan pertimbangan dalam memecahkan masalah yang ada dalam menyusun strategi baru. Proses wawancara ini ditujukan kepada direktur utama, marketing manajer, manajer $\mathrm{R} \& \mathrm{D}$, kepala gudang dan bagian-bagian yang terkait

- Kuesioner

Kuesioner akan disebarkan kepada para customer tetap maupun customer yang memiliki potensi menjadi customer tetap perusahaan tersebut. Sedangkan pertanyaan yang akan diajukan terbagia menjadi enam bagian, diantaranya adalah data pribadi, informasi umum, informasi produk, informasi harga, informasi promosi dan informasi lokasi

\section{TEMUAN DAN PEMBAHASAN}

Berdasarkan penyebaran kuesioner yang dilakukan kepada para customer maupun customer yang memiliki potensi menjadi customer tetap, maka dihasilkan sebagai berikut:

1) Hasil kuesioner berdasarkan bidang usaha, maka sebagian besar bergerak dibidang konsultan (30\%), disusul dengan bidang usaha perhotelan (20\%) dan sisanya terdiri dari berbagai bidang usaha yaitu telekomunikasi, perbankan, institusi pendidikan, perdagangan, migas, kontraktor, pemerintahan, manufaktur serta bidang usaha transportasi.

2) Disamping itu jumlah karyawan dari perusahaan client rata-rata $25-50$ orang (44\%), diikuti oleh perusahaan yang memiliki karyawan sebanyak $50-100$ orang (30\%), dan $10-20$ orang $(16 \%)$, serta lebih dari 100 orang sebesar $10 \%$.

\section{Marketing Mix (Produk, Harga, Tempat, Promosi)}

Berdasarkan hasil kuesioner, yaitu hampir seluruh responden tahu produk merek " $A$ " (96\%) dan hanya 4\% dari responden yang menjawab tidak tahu. Sedangkan jumlah responden yang mengatakan bahwa harga produk merek " $A$ " kompetitif (30\%) dan tidak kompetitif (20\%), sedangkan yang menjawab tidak tahu hanya $4 \%$.

Mengenai perbandingan harga produk merek " $A$ " dengan harga produk merek lain yang sejenis, maka rata-rata responden menjawab harga merek " $A$ " hampir sama $(60 \%)$ dengan merek lain, ada pula yang menjawab lebih mahal (30\%) dan yang menjawab lebih murah hanya sebesar (10\%). 
Berdasarkan hasil kuesioner, maka hampir semua responden mengatakan bahwa furniture merek " $A$ " memberikan potongan harga yang cukup signifikan. Responden yang menjawab bahwa furniture merek " $A$ " tidak memberikan potongan harga dan potongan harga tidak significant sangatlah sedikit (dibawah 10\%) .

Untuk promosi, mayoritas dari responden tidak pernah melihat iklan yang diadakan oleh merek " $A$ " (90\%) dan hanya $20 \%$ responden yang menjawab pernah melihat iklan merek " $A$ "

Dari hasil kuesioner yang terkumpul, mengenai pentingnya showroom bagi perusahaan yang ,memproduksi produk furniture kantor merek " $A$ ", maka rata-rata responden ,menjawab pentingnya showroom bagi furniture merek " $A$ " $(80 \%)$ dan hanya sebagian kecil saja yang menjawab tidak penting $(20 \%)$.

\section{Brand Analysis (Brand awareness)}

Berdasarkan hasil kuesioner dari responden, maka selama ini dimata responden brand vinoti terletak di urutan pertama, disusul dengan brand " $A$ " di urutan kedua, kemudian Bostinco, Datascript, IBU, Ligna, Olympic dan hanya sebagian kecil saja yang menjawab brand lainnya

\section{KESIMPULAN DAN SARAN}

\section{Kesimpulan}

Berdasarkan hasil penelitian dan analisa terhadap kondisi merek " $A$ ”, maka dapat ditarik beberapa kesimpulan sebagai berikut:

1) Umumnya pelanggan merek " $A$ " merasa puas dengan tingkat kualitas dan pelayanan yang telh diberikan selama ini.

2) Menurut sebagian dari pelanggan, harga yang ditawarkan oleh produk merek " $A$ " seringkali tidak sesuai dengan harapan pelanggan.

3) Sebagian besar dari pelanggan " $A$ " tidak mengetahui lokasi pabrik merek " $A$ " ataupun adanya showroom yang dimiliki oleh " $A$ ", sehingga membuat pekanggan sulit untuk melihat contoh produk yang ditawarkan.

4) Proses pengembangan produk baru atau inovasi produk baru dirasakan agak lamban, karena kurangnya dukungan dari top management.

\section{Saran}

Agar hasil analisis dari strategi yang akan dilakukan dapat berjalan dengan baik maka berikut ini penulis ingin memberikan beberapa saran yang kiranya dapat bermanfaat sebagai berikut:

1) " $A$ " harus terus menerus melakukan evaluasi terhadap kinerja yang selama ini telah dicapai, khususnya pada kualitas produk di tingkat harga yang ditawarkan.

2) Untuk tetap bertahan sebagai market leader dari furniture kantor, maka faktor inovasi produk baru harus terus didukung oleh top manajemen agar produk yang dihasikan dapat mengikuti model dan trend saat ini.

3) Kebutuhan akan showroom dirasakan cukup penting, sehingga faktor pembukaan showroom maupun penyeleksian lokasi showroom sangat penting untuk perencanaan jangka panjang furniture merek " $A$ ”. Seperti halnya pesaing " $A$ " yang memiliki showroom seperti vinoti living. 
4) CRM (Customer Relationship Management) merupakan suatu hal yang sangat penting dewasa ini, dengan adanya system CRM yang baik maka perusahaan tersebut dapat bertahan dengan baik, begitu pula dengan furniture merek " $A$ " pemeliharaan hubungan dengan customer menjadi salah satu kunci sukses, baik untuk sekarang maupun yang akan dating. Survey menunjukkan bahwa selama ini pelayananan yang diberikan sudah memuaskan.

\section{DAFTAR RUJUKAN}

Kotler, Philip. Marketing Management. $11^{\text {th }}$ ed. Upper Saddle River, New Jersey: Pearson Education, Inc., 2003.

Kotler, Philip, Swee Hong Ang, Siew Meng Leong, and Chin Tiong Tan. Marketing Management: An Asian Perspective. Singapore: Prentice Hall Pearson Education Asia, 2003.

Treacy, Michael, and Fred Wiersema. Discipline of Market Leader. Boston, MA: Addison Wesley Publishing Co., 1995.

Wheelen, Thomas L., and J. David Hunger. Strategic Management and Business Policy. $9^{\text {th }}$ ed. Upper Saddle River, New Jersey: Prentice Hall, 2004.

Aaker, David A., et al. Marketing Research. $7^{\text {th }}$ ed. New York: John Wiley \& Sons, Inc, 2001.

Kartajaya, Hermawan. Hermawan Kartajaya on Brand. Bandung: PT Mizan Pustaka 2004.

Rangkuti, Freddy. Analisis SWOT Teknik Membedah Kasus Bisnis. Jakarta: PT Gramedia Pustaka Utama, 2004.

http://www.disb2b.com 